\title{
Assessment of environmental performance in recreational areas with the consideration of assimilation potential
}

\author{
Vladimir Kurdyukov ${ }^{1, *}$, Ilona Avlasenko ${ }^{1}$, Lyudmila Avlasenko ${ }^{1}$, and Sergey Kanurny ${ }^{1}$ \\ ${ }^{1}$ Don State Technical University, 1, sq. Gagarina, 344003, Rostov-on-Don, Russia
}

\begin{abstract}
Externalities are a significant feature for recreational tourism. The increase in the specificity of the resource and its significance for the territory may be an additional factor in lowering the requirements for the effective implementation of Coase's idea to solve the problem of externalities. Tourist recreational areas can be an ideal object for implementing Coase's idea of reducing externalities. Given the assessment of environmental quality with the consideration of assimilation potential, it is possible to describe the additional value of changing the volume of environmental pollution for the economic system in the recreational area. The increasing importance of other factors for tourist recreational activities can be factored into the proposed dependency by developing ideas of the assimilation potential of the territory. An approach is proposed for assessing the utility of environmental protection activities in a recreational tourist area which is based on the consideration of changes in the recreational capacities of natural environment and the consequences thereof for the economic system of the territory. The proposed indicator of utility with an adequate assessment of the costs of implementing a project better reflects the cost-effectiveness and results of environmental protection.
\end{abstract}

\section{Introduction}

Technical advance, population growth and consumption of natural resources to meet food, energy and other needs have led to an imbalance in nature. Environmental pollution has become one of the most important problems in the world since the industrial revolution. Water, soil and air pollution are the main types of environmental pollution caused by various new pollutants [1]. All this causes great damage to both humans and the quality of the ecosystem as a whole [2].

Sustainable development of the territory implies maintaining balance between protection and exploitation of natural resources in order to maintain them at a certain level at which environment will not be harmed, favorable conditions will be maintained for the lives of people and other biological species.

The transition to sustainable development requires transformation of existing production and consumption systems, including modification of lifestyles and elimination of

\footnotetext{
${ }^{*}$ Corresponding author: kurdvn@mail.ru
} 
dependency on the finite resources of the planet.

According to the author [3], in order to move towards sustainable development, all countries should:

- determine the balanced volumes of consumption that the planet can sustain over a long period of time;

- find solutions to ensure prosperity and economic growth while reducing energy, raw materials and waste production.

At the same time, states need to promote environmentally conscientious and efficient production, the spread of environmentally friendly technologies, developing countries included, and reduce unsustainable consumption of resources. Society will have to address the growing waste burden by developing a system of environmental policy and management tools on the territory. Sustainable development will not be possible without improved environmental legislation, the use of economic incentives, credit, financial and market mechanisms that will make the environmental value of energy, raw materials, natural resources and waste accumulation visible to the market, which will optimize the use of these factors in solving socio-economic problems.

The constant increase in the needs, well-being and population of developed and developing countries has caused a huge increase in the number of vehicles. This leads to the creation of new roads, the use of new lands and, as a result, to pollution. Therefore, it is necessary to increase the effectiveness of recreational resources, and information regarding recreational experience can help to implement well-informed management decisions [4]. Studies have been conducted by Indian scientists to assess the impact of vehicle emissions on the adaptive and mitigating potential of two tree species planted along the sidelines. To assess the response of trees exposed to roadside traffic flows, the rate of $\mathrm{CO} 2$ assimilation, transpiration rate, water use efficiency, air pollution resistance index, dust removal efficiency and a number of other indicators were studied. Studies have shown that the identified tree species have a high assimilation potential, but it is still necessary to conduct a comprehensive assessment of other resources [5].

American researchers examine the relationship between assimilation of the organization of its environmental management system, the experience that it gains through this, and its environmental performance. Assimilation here means the extent to which the requirements of the management standard are integrated into the day-to-day activities of the enterprise [6].

The issue of pollution is a well-established area of environmental policy at the national and European levels. Establishment of legal limits for the concentration of air pollutants in the environment and the implementation of mitigation strategies for air emissions both nationwide and by specific sources or sectors have led to a reduction in air pollutants and a marked improvement in air quality in Europe [7]

Today, people are beginning to think more about these problems and to look for the most effective ways to address them. One such solution is the willingness of people to pay environmental taxes. The essence of these is to provide the state with payments to combat environmental troubles. Today, studies have shown that residents of more developed countries with an active position in the field of preserving and protecting the environment are more willing to do this, while others prefer to refrain from paying them. This level of responsibility depends directly on the interaction of several components: environmental responsibility, value ideology and, above all, the quality of public administration [8].

Data from scientists at the University of Texas suggests that environmental care is not a major concern for most people. Economic problems far outweigh environmental ones, and the willingness to pay for environmental quality depends directly on the level of economic well-being, in the first place [9].

Research at the Masai Mara National Wildlife Sanctuary in Kenya is an example of an 
effective tool. It is based on the concept of ecosystem services, which is considered as a key concept in environmental policy and is crucial for linking natural and socio-economic systems towards sustainable development. The use of the economic valuation of environmental goods and services is an integral part of the approach. This allows to represent the impact of ecosystem changes on human well-being in monetary terms. The study was aimed at identifying the willingness of wildlife tourists to co-finance restoration and conservation measures in the sanctuary [10]. In general, it is advisable to focus on education and environmental management, the creation of scientific and sustainable environmental consumer values [11].

The importance of green investment increases when the quality of the environment is a factor in generating additional or basic income. The greening of the economy of such territories is an obvious development strategy. An analysis of the volume of green investments shows its spread across different sectors of the economy (figure 1). Identifying the drivers of growth in green investment implies differentiating statistics according to different criteria, such as, for example, territorial specialization.

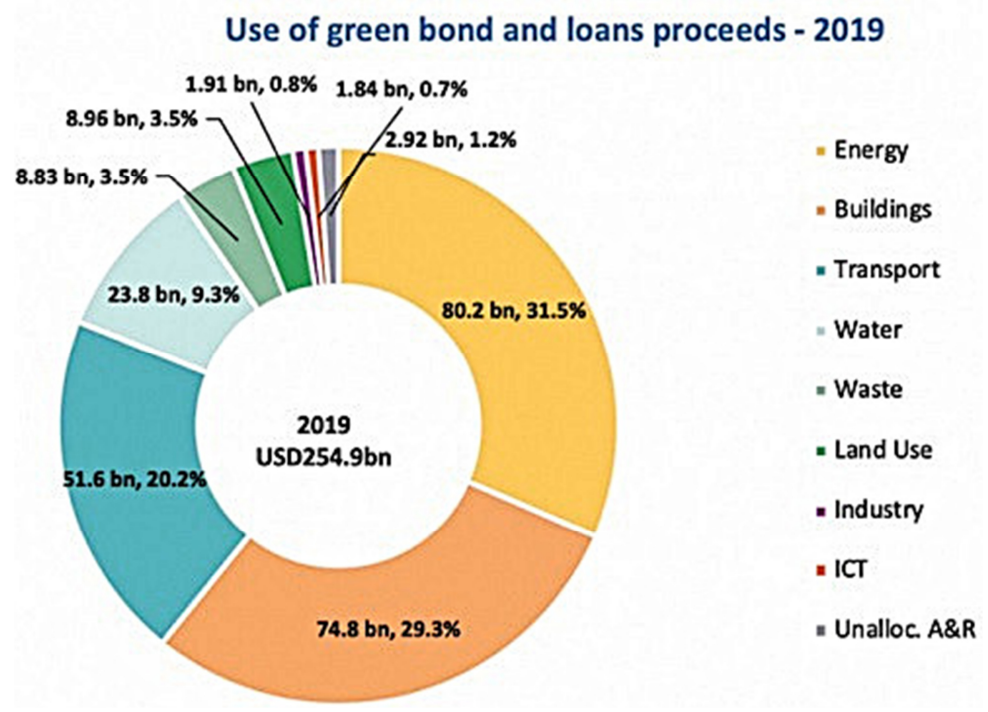

Fig. 1. Use of green bond and loans proceeds - 2019, Source: https://www.climatebonds.net/2020/01/ record-2019-gb-issuance-255bn-eu-largest-market-us-china-france-lead-top-20-national.

Tourism is a branch of economy involving the consumption of goods and services by people in places other than where they live or work. There are various criteria for classifying tourism for this activity. One of the main criteria is the purpose of the trip. There are various objectives, such as recreation, study and sports. In order to analyze the significance of environmental quality factors, we consider the recreational purpose of tourism. An analysis of this type of tourism reveals significant factors both for the sustainable development of the territory in general and for economic growth in particular.

Natural recreational resources are an indispensable condition and material basis for the development of recreational natural resources, one of the areas of tourism. The extent to which recreational needs are met depends on the quality of services that are directly related to the quality of the environment in the region. Environmental protection is therefore a key challenge for the development of tourism in the territory.

Effective environmental protection involves the formation of a management system and mechanisms to reduce damage from emissions of pollutants in the territory. The basic element of the management decision-making system is information support and analysis of 
the source data. The completeness, comparability and adequacy of indicators characterizing the state of the system, in many respects ensure the attainability of management objectives. In other words, shortcomings of the approaches to situation analysis and assessment of the state of the facility create methodological limitations both for determining the most effective management decisions within the budget deficit, and the boundaries of the effectiveness of environmental measures in general.

It should be recognized that serious obstacles to obtaining real information on the environmental status of the territory are the result of a number of deficiencies in environmental management methods and tools. Based on [12], there is no clear correlation between emission standards and the permissible effects of harmful substances on the structural elements of local territories. To address deficiencies, the maximum ecosystem burden must be assessed through the analysis and identification of mechanisms for disposal of pollutants by ecosystem elements. The environmental status parameters proposed in [12] make it possible to determine the maximum acceptable value of anthropogenic environmental impact and to predict the ecological situation in the territory, taking into account the various strategies for ensuring sustainable development.

Considering the relationship between the tourist flow and the possibility of meeting recreational needs, it can be noted that one of the main factors and, in fact, the main product of a recreational territory is the quality of the environment and the recreational capacity of the ecosystem. Environmental quality is a specific product of the recreational area.

The experience of tourist areas shows that in the case of contradictions between environmental pollution and the preservation of the quality of the environment as the main product of the territory (or a significant characteristic of the product), it is possible to establish effective systems of environmental policy instruments and effective environmental projects. For example, the experience of European countries in the 1960s and 1970s in reducing and cleaning up discharges into the Mediterranean Sea against the backdrop of tourism development [13].

Depending on the purpose and restrictions in the territory, a system of internalization of externalities may be formed [14]. Comparison of the effectiveness of investment projects and targeted programs to reduce damage from environmental pollution in the territory is not always in favor of the latter. An additional factor that allows us to determine the importance of environmental programs, management decisions in general for recreational tourist areas and its assessment will be considered in this article.

\section{Methods}

Pollution leads to negative effects and various kinds of damage, in particular to public health, and, if not reflected in the price of the product, to externalities. At a time when environmental quality is the main commodity of the territory (for example, when the economy of the territory is focused on recreational tourism) and the tourism market is developed, the presence of externalities has a direct impact on the value of recreational resources for tourists.

The market will regulate the demand for the product and thus force the processes of contaminant interaction in the territory. The lower the transaction costs, the faster the consequences of environmental pollution will manifest themselves and in the conditions of market interactions the faster stakeholders will respond. Limited rationality in the conditions of possible incompleteness or distortion of information is compensated when the recreational needs of the territory are directly met. Thus, recreational tourist areas are a place where the conclusions of Coase's theorem on the possibilities to negotiate without involving the state are clearly manifested.

Significant characteristics for recreational tourist areas are the quality of services and 
minimal externalities.

Considering these characteristics through the prism of classification and classic examples of externalities (inconvenience, environmental pollution, dangerous behavior, use of a public resource) as proposed by Harvard University Professors of Law and Economics Louis Kaplow and Steven M. Shavell [15], one can distinguish significant conditions of the recreational territory: comfort and convenience, environmental quality, safety, efficient use of public resources.

Meeting recreational needs depends on minimizing externalities in the territory. According to Coase, the solution to the problems of externalities can be found without involving the state through the exchange of property rights to objects generating externalities, provided that these rights are clearly defined and the costs of exchange are negligible.

Reducing transaction costs and developing tourism services accelerates the reduction of externalities, but may increase other transaction and organizational costs.

The specification of property rights (exclusion from access to a resource or the identification of the object, subject and legal ways of transferring property rights [16]) is one of the main tasks of the state. Considering recreational territory, it can be noted that recreational resources can act as an object of property rights, owners of recreational resources can act as subjects, and the market for tourist services can be a mechanism for distributing property rights.

Reducing budget costs for creating conditions for allocating resources becomes possible through the transfer of some project steps to private organizations. In this case, total costs are projected to decrease through more efficient use of funds and a decrease in the role of government agencies to a control function.

Recreational resources, on the one hand, can be a public resource and, on the other, a product to meet the recreational needs of the territory that directly affect the tourism market. Their qualitative component associated with externalities affects both price and demand. At the same time, this market, product features and a high level of communications can simultaneously reduce transaction costs.

Recreational tourism services are reusable goods with a high degree of specificity. Recreational (as well as any tourist) territory may be characterized by specificity of reputation and trademark (non-return or long return on investment if the services are of poor quality), specificity of physical assets and location. When implementing Coase's approach, the specificity of the resource may offset the transaction costs to the territory. The specialization of a territory on a specific resource can ensure consensus decisions, including the reduction of externalities, if this determines the most advantageous behavior strategy.

Recreational tourist areas may be an ideal target for the externalities described by Coase. The specificity of recreational services, on the one hand, does not imply difficulties in specifying property rights and shaping the tourism market. On the other hand, the presence of externalities directly affects the quality of the goods and, within the framework of the market, the effects are felt by stakeholders.

Recreational service providers are interested in reducing externalities in the territory (both at the organizational and territorial levels) to ensure long-term sustainability. However, consumers (here tourists) can also be a source of externalities. For the specification of property rights in recreational areas, the state has to bear significant organizational costs that will reduce transaction costs.

As a result, the formation of market for tourism services contributes to the reduction of externalities according to Coase, on the one hand, and to the reduction of some transaction costs, on the other. Higher organizational costs can reduce externalities, both directly and indirectly, by reducing the transaction sector, which will ultimately improve the market 
situation.

In terms of the concepts of sustainable development and the green economy, anthropogenic impacts on the ecosystem of the territory must be limited to the ecological carrying capacity of the territory [17]. The assimilation potential (the ability and resource of elements of the natural environment to defuse and process harmful substances without changing their essential properties [12]) can be used as a characteristic of the ecological capacity of the territory. Comparing actual environmental pollution with the assimilation potential of the ecosystem makes it possible to assess the environmental quality of the territory. This indicator can be used provided that the permissible load limit (justified maximum emission of pollutants to exclude their dangerous concentration for humans and the environment in the air basin [12]) is changed by technical means or climate change.

The quality of the environment depends on the man-made ecosystem burden, the legal and economic situation in the region, the possibilities of scientific and technological progress, the availability of modern technologies on the domestic market, the specifics of environmental impact assessment, etc. In fact, deficiencies in the natural and economic assessment of pollution damage and in the effectiveness of environmental protection underestimate the importance of social and environmental aspects of life.

However, the effectiveness of environmental management cannot be achieved without assessment, comparison and better choice. Depending on the objective, existing indicators [18] may serve as a criterion for the effectiveness of an investment project, either independently or in an integrated manner. In calculating them, the results of various aspects of management must be adequately taken into account in order to optimize the allocation of material resources (in terms of transition to sustainable development).

In order to compare the cost-effectiveness of various projects, it is important to quantify the total costs and their intended utility. In addition to the costs incurred by the project participants, the costs incurred by external stakeholders related to this activity should be taken into account.

The usefulness of environmental protection activities (as well as any project) for the territory is determined by a set of changes that contribute to the achievement of the goal of sustainable development of the territory (improvement of the situation in the ecological and socio-economic spheres of life). On this basis, the economic utility of the project is an assessment of the performance of the activities on the main vital parameters (economic, environmental, social) of development in the territory. The economic utility of environmental protection measures is characterized by a combination of positive changes in meeting the development needs of the economy, taking into account social interests [19].

Under conditions of minimal information asymmetries, the market in recreational areas forms the conditions for reducing externalities. The reduction of externalities for such a territory increases the income of recreational service providers. In this context, the rational behavior of decision makers will aim at reducing environmental pollution, increasing assimilation capacity and ensuring that stakeholders are informed through various signals. Information openness, development and the alternative of information channels limit the possibilities of using false signals.

Synthesis of perceptions of rational behavior, externalities, and Coase's idea for their reduction, assimilation capacity and environmental quality assessment will allow to determine the additional value and economic utility of environmental pollution modification for the recreational economic system of the tourist territory.

\section{Results}

The tourist flow in the recreational area depends on the degree to which recreational needs are met and on the additional factors (such as, for example, signals) that are perceived by 
consumers to some extent. Satisfying recreational needs in a given area are associated with the recreational capabilities of the ecosystem. Changes in the recreational capacity of an ecosystem may affect the timing and efficiency of recovery and, consequently, the extent to which recreational needs are met.

The improvement of the quality of the product or service in the market conditions in our case will affect the growth of the tourist flow and/or the price. This, in turn, will have an impact on the growth of industry income in the territory and, in general, on the gross regional product.

Under the conditions that are reflected in Coase's theorem, the utility of environmental quality change can be expressed by prognosis and indirect estimation of the results of changes in the market situation on the territory.

Environmental quality directly affects the quality of tourism (recreational) services provided. Therefore, consumer behavior and their impact on the income of recreational areas (with minimal transaction costs) will be directly proportional to the quality of the environment. Thus, it is possible to express the economic value of changes in environmental pollution to the recreational area. At the same time, damage to the economic system from environmental degradation can be addressed through this relationship.

Correction coefficients are used to show the degree of ignorance of the process. It is proposed to determine the annual economic utility of recreational environmental activities from the following expression:

$$
U_{p}=U_{1} * U_{2} * f^{\prime}\left(C_{t} / M_{t}\right) * D
$$

where $U_{p}$ is the economic utility of the project (or management system, management decision system) for recreational tourism in the territory, monetary units/year;

$U_{l}$ - the correction factor, reflecting the impact of recreational abilities on the income from tourism in the territory;

$U_{2}$ - the correction factor reflecting the dependence of the recreational capacity of the ecosystem (or the quality of the services provided and the attractiveness of tourism) on the environmental quality of the territory;

$M_{t}$ - environmental pollution in the period $\mathrm{t}$ (it is assumed that it is not equal to 0 since in living systems there are waste products of the ecosystem elements that are integrated into the cycles of energy and substances), $\mathrm{kg} /$ year;

$C_{t}-$ the assimilation potential of the ecosystem over a period $\mathrm{t}$ (can be calculated based on assessment of the ability of ecosystem elements to defuse harmful substances), $\mathrm{kg} / \mathrm{year}$;

$C_{t} / M_{t}$ - environmental quality characteristics in the territory over a period t;

$f^{\prime}\left(C_{t} / M_{t}\right)$ - changes in environmental quality (the indicator characterizes the results of environmental and management decisions over a period $\mathrm{t}$ );

$D$ - income from recreational tourism on local territory, monetary units/year.

The proposed relationship of economic utility defines the added value of increasing the ability of the economic system to meet recreational needs.

Empirical relationships for different territories can be used to determine the values of the correction coefficients.

The value of coefficient $U_{I}$ depends on the subjective perception of consumers and their choice. The behavior of consumers of tourism services is influenced by information support about various factors in a particular territory. The conditions for the availability of information make it possible to study rational behavior in the territory by means of correlation and regression analysis and to determine the value of correction factors. With minimal transaction costs, the coefficients will be about 1 . Under the conditions of informational restrictions, the coefficients can be influenced by information asymmetries and PR tools.

In addition to the features of ecosystem elements and artificial objects with recreational 
capabilities, coefficient $U_{2}$ can be influenced by information asymmetries of stakeholders and, in general, transaction costs.

If there is no change in the $C_{t} / M_{t}$ indicator or cannot be, the improvement of the environment will not increase the income from tourism and other opportunities for influencing the quality of the services provided should be exploited.

It is important to note that planned or implemented management decisions may have negative economic benefits for the recreational area, even without taking into account the total costs associated with their implementation.

Environmental pollution of the territory within the assimilation potential of the ecosystem (or the maximum permissible load [12]) allows the use of a compensatory environmental mechanism to address possible environmental externalities. This may serve as an incentive for the development of recreational tourism industry and an indicator of the development of an appropriate target program.

In determining the optimal level of environmental pollution in a recreational tourist area, it is necessary to take into account the possible lost environmental benefits from increased pollution. In the context of the development of green technologies, this will gradually shift the optimal level of anthropogenic pollution in the territory to assimilation potential or to zero.

As a result, an approach is proposed for assessing the utility of environmental protection activities in a recreational tourist area, which is based on the consideration of changes in the recreational capacities of the natural environment and its consequences for the economic system of a tourist territory. The use of the proposed approach for assessing the economic impact of measures which affect environmental pollution and the tourist attractiveness of the territory will make it possible to increase competitiveness and investment attractiveness, provide gross product growth, tax deductions and employment due to additional jobs.

\section{Conclusion}

Due to the fact that natural environment is able to neutralize waste products, the assimilation potential must be considered a strategic resource of the territory. In order to reduce environmental tensions, environmental protection should be based on the properties of natural objects, and environmental measures should be evaluated using scientifically based criteria, the determination of which can be based on the assimilation potential and the maximum permissible ecosystem load.

The assessment of environmental performance should be based on a set of environmental quality changes that promote environmentally sustainable development and ensure that social interests of the area in question are met. In order to rationally select alternative projects, it is suggested to evaluate the results of their implementation according to the formula for calculating economic utility.

In order to find efficient environmental solutions, an indicator of the economic utility of environmental protection should be used, reflecting the additional consequences of the implementation of various projects, which would help to ensure a rational distribution of cash flows. The proposed indicator of utility with an adequate assessment of the costs of implementing a project better reflects the cost-effectiveness and results of environmental protection.

In today's dynamic environment, the risks of changing the importance of additional factors in the development of the territory must be taken into account. In this regard, the proposed dependency can be applied to the expansion of the considered factors.

Tourism, on the one hand, involves ensuring safety for tourists as one of the elements of the quality of services provided. On the other hand, with the help of managerial decisions it is necessary to ensure that the impact of tourism and the movement of masses of people is 
safe for the local population and territory. The proposed dependency can be used to assess the effects of environmental pollution. However, in addition to environmental impacts, there are other territorial impacts that can be associated with the externalities considered earlier. In this case, it is necessary to consider the assimilation potential of the territory to assess the sustainability of the territory: the ability to offset all the consequences (not only environmental) of anthropogenic impact on the territory and integrate energy, material and information flows into the everyday processes of the socio-economic system.

The assimilation capacity of the territory allows externalities to be transferred to organizational costs with no adverse effects for the territory.

To assess the additional value of the tourism strategy and the movement of masses of people in the territory from the point of view of sustainable development, other elements of the assimilation potential of the territory (in addition to the assimilation potential of the ecosystem) can be used in formula (1).

Externalities are a significant feature for recreational tourism. The increase in the specificity of the resource and its significance for the territory are the conditions under which the requirements for the effective implementation of Coase's idea to solve the problem of externalities without government intervention are reduced. Tourist recreational areas can be an ideal object for implementing Coase's idea of reducing externalities. Ownership of recreational resources in these territories does not imply complexity for specification, and the specificity of the resource does not allow the growth of the transaction sector.

Changes in environmental quality proportionally affect the gross income from recreational tourism in the territory. Given the assessment of environmental quality against assimilation potential, the value of changing the volume of environmental pollution for the economic system in the recreation area can be described.

An examination of the characteristics of this dependency in different territories reveals the significance of the environmental factor for different tourist destinations. The increasing importance of other factors for tourist recreational activities can be taken into account in the proposed dependency by developing ideas on the assimilation potential of the territory.

\section{Acknowledgment}

The reported study was funded by RFBR according to the research project № 19-01000904 .

\section{References}

1. C. Mustansar Hussain, R. Keçili, Modern Environmental Analysis Techniques for Pollutants, 1-36 (2020)

2. A. Fugiel, D. Burchart-Korol, K. Czaplicka-Kolarz, A. Smoliński, Journal of Cleaner Production 143, 159-168 (2017) doi:10.1016/j.jclepro.2016.12.136

3. A.J. Wieczorek, Environmental Science \& Policy 84, 204-216 (2018) doi.org/10.1016/j.envsci.2017.08.008

4. P.J. Fix, J.J. Brooks, A.M. Harrington, Journal of Outdoor Recreation and Tourism 23, 16-25 (2018) doi:10.1016/j.jort.2018.04.004

5. H. Singh, M. Yadav, N. Kumar, A. Kumar, M. Kumar, PLOS ONE 15(1) (2020) doi:10.1371/journal.pone.0227380

6. G. Lannelongue, J. Gonzalez-Benito, O. Gonzalez-Benito, C. Gonzalez-Zapatero, Journal of Environmental Management 147, 203-212 
(2015) doi:10.1016/j.jenvman.2014.04.035

7. A. Marcoa, Ch. Proiettib, A. Anava, Environment International 125, 320-333 (2019)

8. D. Davidovic, N. Harring, S.C. Jagers, Environmental Politics, 1-23 (2019) doi:10.1080/09644016.2019.1606882

9. J. Polinard, R. Wrinkle, Environment International 4(4), 325-330 (1980) doi:10.1016/0160-4120(80)90084-7

10. R. Pedroso, J. Biu Kung'u, Journal of Sustainable Tourism, 1-18 (2019) doi:10.1080/09669582.2019.1593991

11. J. Li, L. Ren, M. Sun, Journal of Cleaner Production (2019) doi:10.1016/j.jclepro.2019.118259

12. L.Kh. Badalyan, V.N. Kurdyukov, A.M. Ovcharenko, Y.V. Gorshkova, Sustainable development of mountain territories 10-2(36), 307-314 (2018) doi:10.21177/19984502-2018-10-2-307-314

13. E. González et al., Desalination and Water Treatmen 31, 197-205 (2011) doi: $10.5004 /$ dwt.2011.2361

14. V. Kurdyukov, L. Badalyan, I. Avlasenko, L. Avlasenko, S. Kanurny, IOP Conf. Series: Earth and Environmental Science 403 (2019) doi:10.1088/1755$1315 / 403 / 1 / 012080$

15. L. Kaplow, S. Shavell, Handbook of Public Economics 1(3), 1661-1784 (2002)

16. V.V. Tsushko, Property rights specification and protection in transition economies Actual Problems of Economics 159(9), 141-148 (2014)

17. V. Glinskiy, L. Serga, M. Khvan, Assessment of Environmental Parameters Impact on the Level of Sustainable Development of Territories Decoupling Growth from Resource Use 40, 626 - 631 (2016) doi:10.1016/j.procir.2016.01.145

18. W.E. Ferson, Investment Performance Evaluation Annual Review of Financial Economics 2(1), 207-234 (2010) doi:10.1146/annurev-financial-120209-134007

19. V.N. Kurdyukov, L.H. Badalyan, A.M. Aleynikova, Vestnik of Don State Technical University 3(64), 87-93 (2012) https://vestnik.donstu.ru/jour/article/view/573/573 